\title{
Braillearning: Software para simular a máquina de escrever em Braille
}

\author{
Kayo C. Santana, Claudia P. Pereira, Beatriz S. de Santana \\ Programa de Pós-Graduação em Ciências da Computação - Universidade Estadual de \\ Feira de Santana (UEFS) \\ Feira de Santana - BA - Brasil \\ \{kayosantana94, caupinto.sena\}@gmail.com, beatrizsantana@ieee.org
}

\begin{abstract}
Braille is an important means of communication used by people with visual impairment. Some technologies already created can help them in the learning process of Braille, such as the slate and the stylus, and the Braille typewriter machine. This last one, even presenting itself as a better alternative to Braille writing, it is not very accessible to everybody due its high values. In this paper, it will be presented Braillearning, a free software solution that simulates the use of a typewriter, helping people with visual impairments in the process of social and digital inclusion.
\end{abstract}

Resumo. Braille é um importante meio de comunicação utilizado por pessoas com deficiência visual. Algumas tecnologias já criadas podem auxiliar no processo de aprendizagem do Braille, como exemplos, a reglete e a punção, $e$ a máquina de escrever em Braille. Esta última, mesmo se apresentando como uma melhor alternativa para a escrita Braille, não é muito acessivel devido aos altos valores de mercado. Neste artigo, será apresentado o Braillearning, uma solução gratuita desenvolvida em software, que simula o uso da máquina de escrever em Braille, auxiliando, dessa forma, a inclusão social e digital de pessoas com deficiência visual.

\section{Introdução}

Com o passar dos anos, a conscientização da necessidade de proteção ao direito das minorias é cada vez mais evidente. Organizações mundiais, como a ONU (Organização das Nações Unidas), estabeleceram leis e diretrizes que versam sobre os direitos das pessoas com deficiência e propõe metas para incluí-las socialmente, possibilitando que, com os devidos cuidados, deficiência alguma venha diminuir a qualidade de vida de qualquer pessoa [CNAIPD, 1981; Mazzilli, 1999].

A resolução 31/123, estabelecida pela Assembleia Geral das Nações Unidas, traz como um dos objetivos principais a ajuda aos deficientes no seu ajustamento físico e psicossocial na sociedade e também a promoção de todos os esforços globais, para proporcionar-lhes asseguração da sua plena integração na sociedade [CNAIPD, 1981].

Entendendo que os tipos de deficiências e as maneiras de sanar a problemática em torno da acessibilidade para cada uma não são homogêneas, este trabalho trata especificamente da deficiência visual (DV).

A ONU estima que, dentre a população mundial, 39 milhões de pessoas são cegas e outras 253 milhões possuem algum tipo de deficiência visual. Sabe-se que uma 
VIII Congresso Brasileiro de Informática na Educação (CBIE 2019)

Anais do XXX Simpósio Brasileiro de Informática na Educação (SBIE 2019)

alternativa da representação do alfabeto e dos símbolos numéricos para esse público é o Braille, que fornece uma representação tátil que possibilita a alfabetização e a integração social das pessoas com DV. O Braille é essencial na educação desse público, pois possibilita a livre expressão de opinião e o acesso às informações [ONU, 2019].

Nesse sentido, a criação de ferramentas que possam auxiliar o ensinoaprendizagem da linguagem Braille para pessoas com DV é uma forma de possibilitar a inclusão das mesmas no ambiente educacional, assim como abrir oportunidades de autonomia. Nesse contexto, o uso de tecnologias da informação e comunicação (TICs) para esse objetivo possibilita, não só a inclusão social, como também a digital.

Por outro lado, equipamentos de custos elevados para o ensino de Braille, tais como a máquina Braille, acabam dificultando a jornada da pessoa DV rumo ao aprendizado. Considerando o contexto geral, esse trabalho propõe o uso TICs como maneira de aprender o Braille, promovendo a inclusão sócio digital de pessoas com DV. Para tanto, foi criada a ferramenta gratuita, chamada Braillearning, que simula o uso da máquina de Braille, com o intuito de auxiliar a aprendizagem e a memorização do Braille, assim como o desenvolvimento de habilidades relacionadas ao manuseio da máquina Braille.

Este artigo apresenta, além desta seção de introdução, os conceitos sobre acessibilidade e inclusão social de pessoas com deficiência visual, todos os procedimentos seguidos para a elaboração deste trabalho, apresentação da ferramenta desenvolvida, bem como seu processo de validação, além dos resultados obtidos através do uso da ferramenta pelo público-alvo.

\section{Inclusão Social e Acessibilidade para Pessoas com Deficiência Visual}

A resolução XXX/3.447, aprovada em 1975 pela Assembleia Geral da Organização das Nações Unidas, trouxe a declaração dos direitos das pessoas com deficiência, dentre os quais está o direito de desfrutar de uma vida decente, tão normal e plena como a de seus concidadãos. Essa resolução, junto com a 31/123, viabilizou a necessidade de medidas para melhorar a vida de pessoas deficientes [ONU, 2019].

Nesse sentido, promover meios para a inclusão social de pessoas com deficiência visual (DV) se faz necessário no sentido de possibilitar que tenham uma vida normal e com os mesmos direitos que os outros cidadãos. $\mathrm{O}$ ensino e a educação são formas de garantir os direitos humanos e, deste modo, não podem ser exclusivos de pessoas que não possuem deficiência. Para tanto, é importante a adequação da forma de aprendizado para pessoas com qualquer tipo de restrição [Figueiredo e Rosa, 2014].

O Braille foi criado com o intuito de que os cegos tivessem acesso à leitura por meio de pontos de alto relevo de significação tátil, utilizando seis pontos em duas colunas, possibilitando a representação de letras do alfabeto, sinais de pontuação e números. Ele possibilita não apenas o acesso à comunicação, mas também a identificação de locais e a abertura de outras possibilidades que são comuns aos videntes, como, por exemplo, o desenvolvimento profissional [Roth e Fee, 2011].

A escrita em Braille é possibilitada por diversos modos, o mais antigo e mais utilizado é a reglete e a punção. Nesse método, o aprendiz deve prender o papel na reglete, uma espécie de régua que possui celas de Braille, e efetuar os pontos com a punção, formando as letras e os símbolos desejados. Tal método, além de ser 
VIII Congresso Brasileiro de Informática na Educação (CBIE 2019)

Anais do XXX Simpósio Brasileiro de Informática na Educação (SBIE 2019)

considerado altamente propenso a erros, não é indicado para crianças já que a punção se trata de um ferro pontiagudo [Resende e Filho, 2012]. Outra opção para o desenvolvimento da escrita, um pouco mais sofisticada, é a chamada máquina de Braille. Esta máquina possui seis botões que permitem a escrita por meio do toque simultâneo em suas teclas.

Com o avanço e a integração das tecnologias na sociedade, é possível pensar, não somente na inclusão social das pessoas com DV, como também na inclusão digital. Nesse sentido, Kavčič, Pesek e Marolt (2017) apresentam em seu trabalho um sistema em esloveno, através do qual é possível realizar treinamentos em Braille, digitação em teclados e alguns jogos com o intuito de exercitar a memória da pessoa com DV. A plataforma se aproxima da ideia proposta no presente artigo, tendo como principal diferença o idioma, já que o Braillearning é voltado para o público brasileiro. Além de softwares, existem também soluções computacionais que fazem uso do hardware para auxiliar a aprendizagem do Braille, utilizando-se de um acessório que permite a entrada de dados, que são tratados por um sistema computacional [Kalra et al., 2007; Osuch e Sinha, 2013; Pauta; Vélez; Serpra-Andrade, 2016].

\section{Metodologia}

Nesta seção, serão abordados os passos para a construção e a validação da ferramenta Braillearning. A Figura 1 mostra os passos desde a concepção de ferramenta até a criação de sua versão atual, que foi testada pelo seu público alvo.

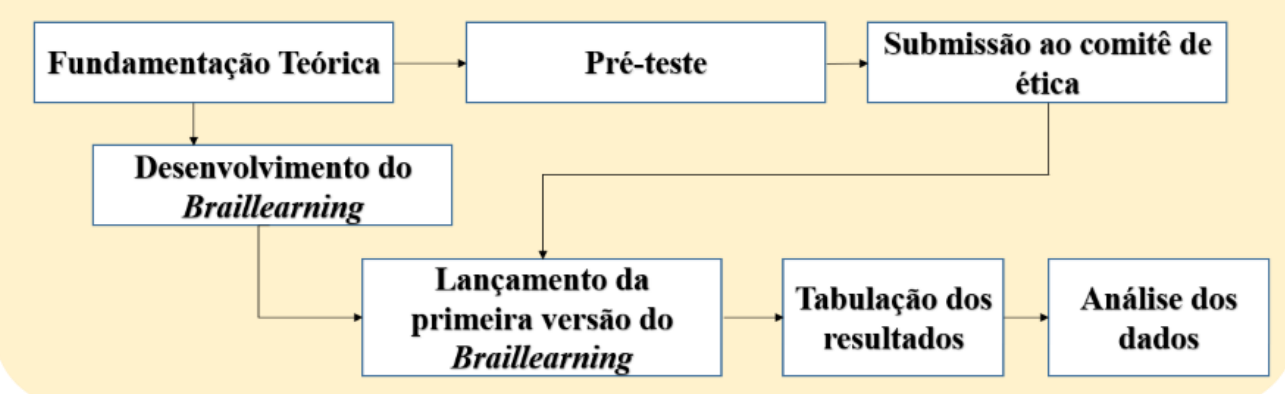

Figura 1. Metodologia do Braillearning. Adaptado de [Santana, 2018]

Como pode ser percebido na Figura 1, a fundamentação teórica foi necessária para o desenvolvimento da ferramenta, não apenas sobre as tecnologias utilizadas, como também sobre a escolha das melhores para incluir pessoas com deficiência visual (DV), estudos sobre suas necessidades específicas e também sobre funcionamento do Braille.

$\mathrm{Na}$ etapa de pré-teste, foi realizada a criação dos instrumentos de coleta de dados. Neste momento, foi criado um questionário que possui 16 questões, abordando um pouco sobre o perfil do candidato (P1 até $\mathrm{P} 3$ ), seu conhecimento sobre tecnologias e Braille (P4 até P6) e, por fim, perguntas sobre sua experiência com a ferramenta (P7 até P16), conforme mostra o Quadro 1.

Quadro 1. Perguntas do questionário de validação [Santana, 2018].

P1- Qual a sua faixa etária?

P2- Qual das definições abaixo você se enquadra?

P3- Você já utilizou a máquina de escrita em Braille? 
VIII Congresso Brasileiro de Informática na Educação (CBIE 2019)

Anais do XXX Simpósio Brasileiro de Informática na Educação (SBIE 2019)

P4- Você está acostumado com o uso de computador?

P5- Você está acostumado com o uso de tecnologias assistivas?

P6- Você costuma utilizar ferramentas digitais para auxiliar no processo educacional (ensino e aprendizagem)?

P7- Você acredita que o Braillearning pode auxiliar as pessoas a escrever em Braille através da máquina de escrever?

P8- Sobre sua experiência com a ferramenta, você gostou dos modos de uso que ela oferece (tutorial, palavra e livre)?

P9- Sobre sua experiência com a ferramenta, é correto afirmar que através dela foi possível aprender de maneira divertida?

P10- Sobre sua experiência com a ferramenta, você gostaria de utilizá-la mais vezes?

P11- Sobre sua experiência com a ferramenta, pode-se afirmar que você gostou desse momento?

P12- Você concorda que a ferramenta possibilita ao usuário uma experiência parecida com a do uso da própria máquina?

P13- Você concorda que com o uso do Braillearning é possível aprender a utilizar a máquina de Braille?

P14- Você concorda que através do uso do Braillearning é possível aprimorar o manuseio da máquina de Braille (escrever mais rápido, maior precisão)?

P15- O Braillearning possui funcionalidades que garantem acessibilidade e, portanto, integram pessoas com deficiência visual?

P16- Sinta-se a vontade para nesse espaço deixar algum comentário sobre a ferramenta (crítica, elogio, sugestão).

A pergunta 1 apresentava como respostas: Menor que 18; Entre 18 e 24; Entre 25 e 39; Maior que 39 e Prefiro não responder. Já a pergunta 2, que pretendia compreender o grau de deficiência do voluntário possuía as opções: Enxergo normalmente; Dificuldade moderada para enxergar; Dificuldade severa para enxergar e Sou totalmente cego. A pergunta 3 sugere apenas as respostas de Sim/Não. Por fim, todas as outras perguntas ( $\mathrm{P} 4$ até $\mathrm{P} 15)$ foram feitas com base na escala Likert, oferecendo 5 níveis de resposta, sendo estes: Discordo totalmente; Discordo parcialmente; Indiferente; Concordo Parcialmente, Concordo Totalmente.

O Braillearning apenas foi lançado para a realização dos testes após sua aceitação pelo comitê de ética, e a assinatura do TCLE (Termo Consentimento Livre e Esclarecido) pelos participantes (cópia em Braille ou lida por pessoa de confiança do DV). A pesquisa foi realizada com 20 estudantes em diferentes idades do CAP-DV, um centro de apoio pedagógico, especializado em atender pessoas com DV, localizado em Feira de Santana. Após reunir todas as respostas, foi possível agrupar os dados, criando informações que auxiliaram no processo de avaliação e de ajustes na ferramenta.

\section{Braillearning}

O software apresentado foi desenvolvido para auxiliar pessoas com deficiência visual (DV) no uso da máquina de escrever em Braille, além de ajudá-los na memorização do alfabeto Braille.

É importante enfatizar que a máquina de escrita em Braille é um modo mais rápido e melhor de escrita em Braille, se comparado com a reglete e a punção, porém ela não é acessível para boa parte do público com DV, devido ao seu alto custo, possuindo poucos exemplares nos centros de apoio, sendo muitas vezes necessário o revezamento do seu uso entre os estudantes que os frequentam. O Braillearning se apresenta como uma solução em software gratuita para simulação do seu uso. 
VIII Congresso Brasileiro de Informática na Educação (CBIE 2019)

Anais do XXX Simpósio Brasileiro de Informática na Educação (SBIE 2019)

A aplicação é dividida em três módulos (Figura 2) que proporcionam diferentes níveis e experiências de aprendizagem e prática. Nessa seção, serão abordados como é realizada a simulação da máquina e como cada um dos seus modos funciona.

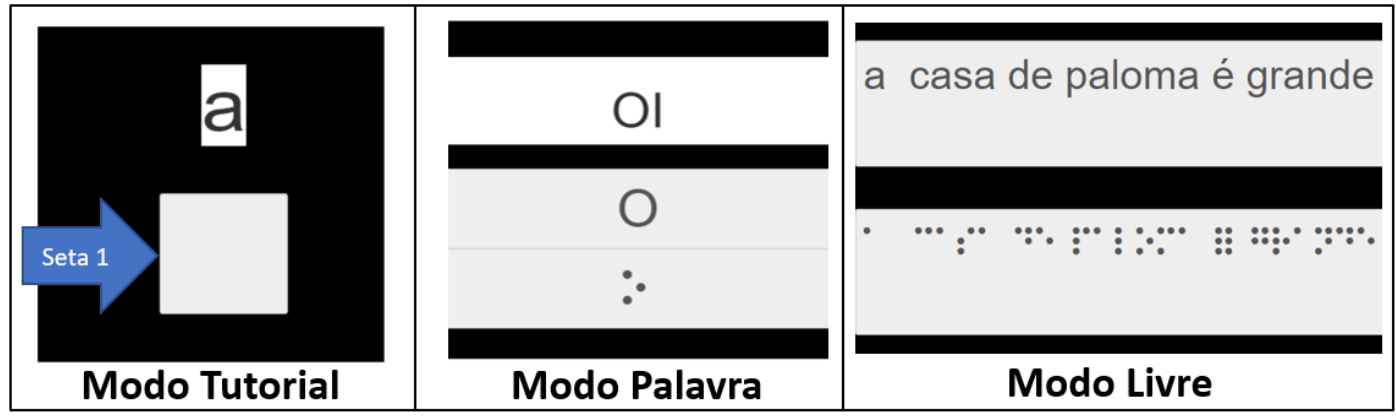

Figura 2. Modos de operação do Braillearning. Adaptado de [Santana, 2018].

\subsection{A simulação da máquina}

O alfabeto Braille é construído baseado na combinação de seis pontos em relevo, que são organizados em uma tabela de três linhas e duas colunas, conhecida como cela Braille (Figura 3).

\begin{tabular}{|l|l|}
\hline 1 & 4 \\
\hline 2 & 5 \\
\hline 3 & 6 \\
\hline
\end{tabular}

Figura 3. Exemplo de célula Braille [Almeida e Paula, 2008].

A combinação dos seis pontos na cela Braille é responsável por codificar o alfabeto Braille, representado na Figura 4, com os círculos preenchidos simbolizando os relevos que são responsáveis pela formação de cada caractere.

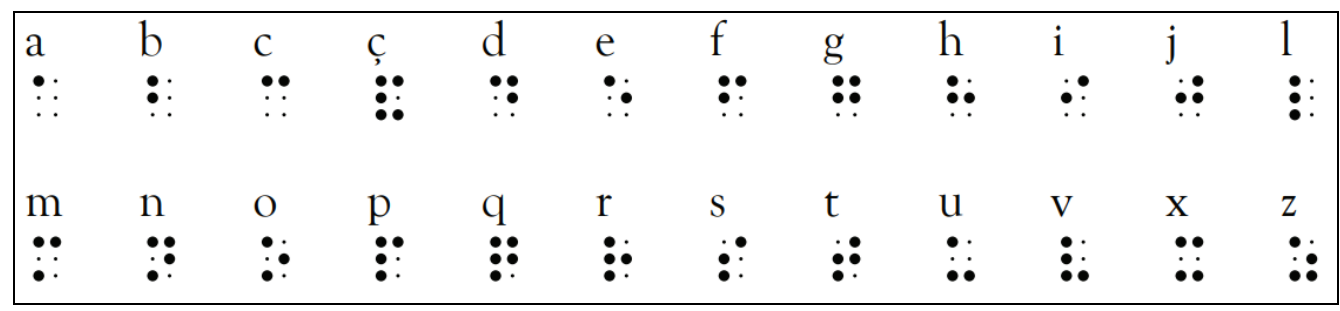

Figura 4. Exemplo do alfabeto Braille [MEC, 2006].

Ao relacionar a Figura 3 com a Figura 4, é possível escrever em Braille através da máquina, representada na Figura 5. Quando o usuário pressiona simultaneamente os botões responsáveis por cada ponto (do 1 ao 6), a máquina faz um relevo nos locais dos respectivos pontos, representando a letra formada através da combinação. Por exemplo, se os botões 1 e 2 forem pressionados, será formada a letra ' $b$ ' do alfabeto Braille.

Para simular esses botões, no desenvolvimento do Braillearning foram utilizadas as teclas ' $\mathrm{F}$ ', ' $\mathrm{D}$ ', 'S', 'J', ' $\mathrm{K}$ ' e ' $\mathrm{L}$ '. Através da ferramenta, é possível realizar a escrita com uma experiência semelhante à da máquina, neste caso, se o usuário desejar escrever a letra ' $b$ ', ele deverá pressionar simultaneamente as teclas ' $F$ ' e ' $D$ ' em seu teclado. As teclas são associadas conforme mostra a Figura 5. 


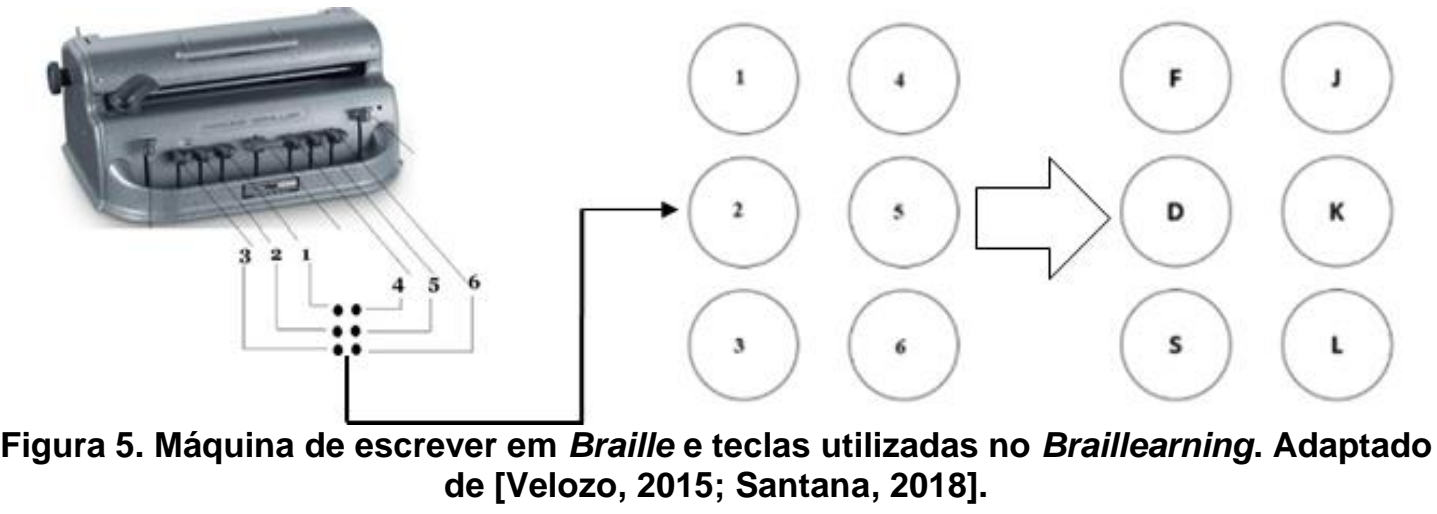

Enquanto na máquina de escrita o usuário recebe a saída no papel em forma de relevo, no Braillearning, ele receberá a saída em forma de áudio sintetizado. É importante lembrar que a leitura é um passo fundamental na aprendizagem do Braille e não deve ser ignorada. Mesmo utilizando o Braillearning, o usuário deverá também ter acesso à máquina ou a reglete e a punção, para desenvolver suas habilidades táteis.

\subsection{O modo tutorial}

O modo tutorial é focado no processo de aprendizagem da codificação Braille e como funciona a máquina. $O$ usuário recebe do sistema (através de áudio e imagem) um caractere e ele terá que pressionar as teclas responsáveis pela formação deste caractere em Braille. Ao acertar, um novo caractere é solicitado, sequencialmente ou aleatoriamente (dependendo de sua escolha). Em caso de erro, é exibido um efeito de erro e o usuário poderá novamente realizar a mesma combinação.

Este modo objetiva a aprendizagem do Braille. Se o usuário precisar de ajuda (dica) para lembrar-se das combinações, ele poderá solicitá-la, através de um atalho, a qualquer momento, sendo lembrado das teclas responsáveis pela formação do caractere, auxiliando-o na memorização (Figura 2). Como pode ser visto na Figura 2, o sistema solicitou as teclas responsáveis pela criação da letra 'a'. No espaço em branco (seta 1) aparecerá a correspondência Braille, caso o usuário digite a combinação de teclas corretas, que, neste caso, é a letra 'F' (Figura 4), correspondente ao ponto 1 (Figura 5).

\subsection{O modo palavra}

Neste modo, o sistema disponibiliza ao usuário uma palavra sorteada na base de dados do Braillearning. Enquanto o usuário estiver digitando a palavra, caso esteja acertando, ele receberá como saída o caractere digitado e um efeito de som de sucesso; caso contrário, será disponibilizado um efeito de erro e ele deverá digitar um novo caractere.

O usuário poderá solicitar do sistema, a qualquer momento (através de atalhos), informações sobre as letras que já foram digitadas, para que possa relembrar letras erradas digitadas e possa ser guiado por áudio no processo de digitação da palavra. Ele também poderá solicitar que o sistema reproduza novamente a palavra sorteada. Ao finalizar uma palavra e pressionar a tecla enter, se sua entrada (palavra digitada) estiver correta, será reproduzido um som de aplausos e outra palavra será sorteada.

A Figura 2 apresenta o modo palavra, com o sorteio da palavra "oi". Após o usuário digitar a combinação correta para a letra "O", ele recebe como resposta o áudio sintetizado, e também a representação visual nos alfabetos latino e Braille. 
VIII Congresso Brasileiro de Informática na Educação (CBIE 2019)

Anais do XXX Simpósio Brasileiro de Informática na Educação (SBIE 2019)

\subsection{O modo livre}

Por fim, como pode ser visto na Figura 2, o modo livre pode ser utilizado para representar melhor a máquina de escrever Braille, uma vez que o usuário pode digitar livremente palavras, frases e exercícios de matemática, de acordo com seu interesse.

Como nos outros modos, o usuário é guiado tanto por elementos auditivos como também visuais. Com o uso de dois diferentes atalhos (i.e., aspas simples, control esquerdo), o usuário poderá sintetizar todo o conteúdo digitado até o momento, ou apenas soletrar a última palavra digitada.

Neste modo, usuários também podem reproduzir operações matemáticas, através de números (de 0 a 9) e símbolos. Para reconhecer o número, o sistema necessita receber o caractere responsável pela identificação de um número, assim como no Braille, e, após isso, a combinação responsável por formar cada um dos números.

\section{Validação do Braillearning}

Depois de finalizado o desenvolvimento, o Braillearning foi disponibilizado para ser testado no Centro de Apoio Pedagógico ao Deficiente Visual (CAP-DV), da Fundação Jonathas Teles Carvalho, em Feira de Santana. A ferramenta foi utilizada por 20 pessoas com deficiência visual (moderada, severa e totalmente cegas) em diversas faixas etárias. Todas elas já sabiam ler e escrever em Braille e 95\% dos sujeitos já tinham tido experiência anterior com a máquina de escrever em Braille.

Para a análise das respostas, foram utilizadas as perguntas conforme enumeradas no Quadro 1, disponibilizado na seção de metodologia. Pelo Gráfico 1, percebe-se que alguns dos participantes ainda não estavam familiarizados com o uso de tecnologias em sua rotina. Ainda assim, mesmo os que não utilizavam o computador, conseguiram, através do mesmo, simular o uso da máquina com o Braillearning (Gráfico 2).

\section{Gráfico 1 - Gráfico de análise do uso de tecnologias e ferramentas pelos participantes da pesquisa [Santana, 2018].}

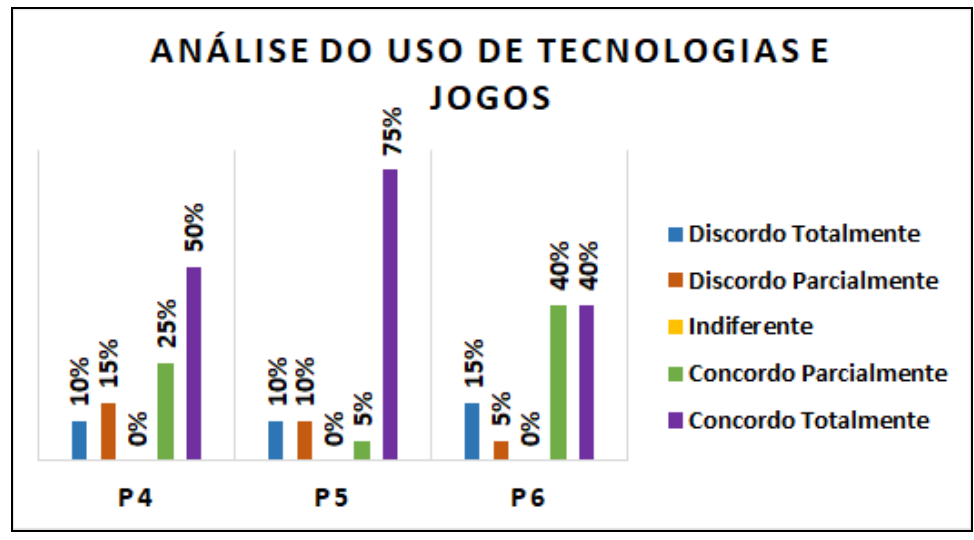

A validação da ferramenta (Gráfico 2) buscava verificar se suas funcionalidades poderiam ser realizadas corretamente, se estavam adequadas ao seu propósito e também avaliar as expectativas do usuário.

Gráfico 2 - Análise da aceitação da ferramenta pelo público alvo. Adaptado de [Santana, 2018]. 
VIII Congresso Brasileiro de Informática na Educação (CBIE 2019)

Anais do XXX Simpósio Brasileiro de Informática na Educação (SBIE 2019)

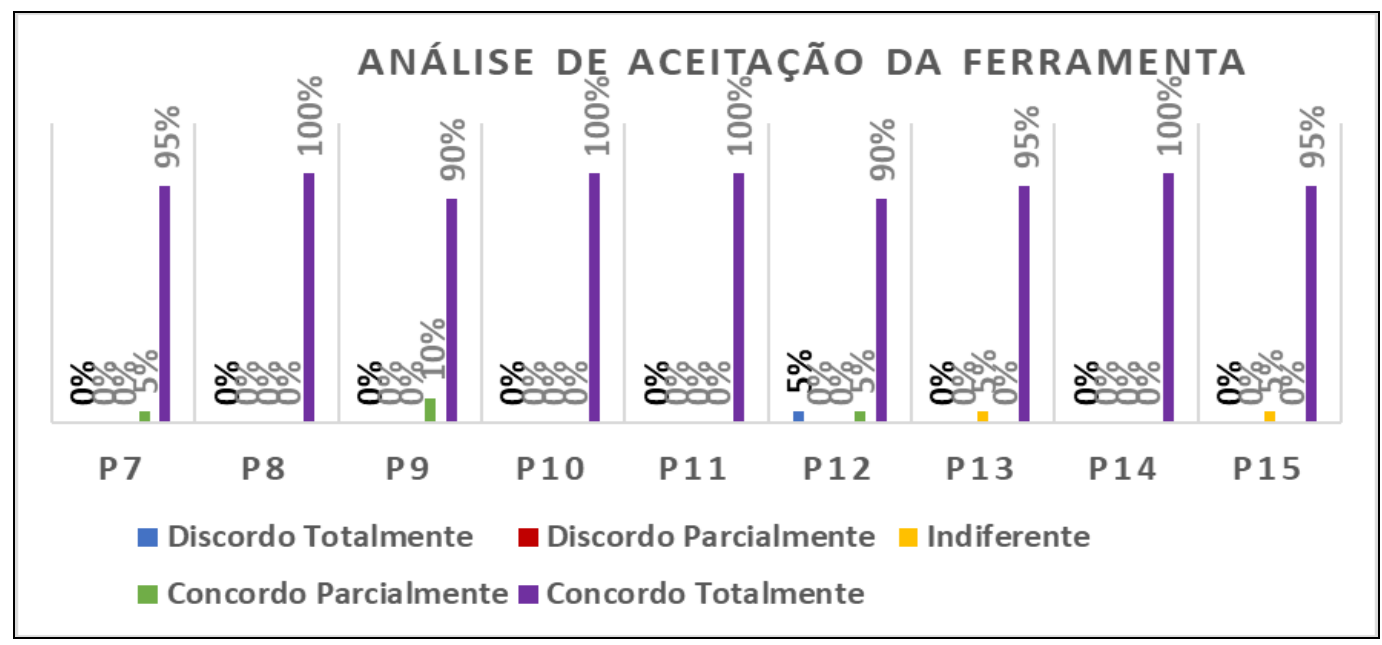

Através do Gráfico 2, é possível afirmar que, para os usuários, a ferramenta auxilia na escrita do Braille (P7) e na aprendizagem de uso da máquina, através de uma maneira lúdica (P9). As reflexões permitem ainda confirmar que os usuários gostaram dos modos propostos (P8) e do momento de experiência com a ferramenta (P11), querendo inclusive utilizá-la mais vezes (P10), o que mostra o bom índice de aceitação.

Además, com a análise do Gráfico 2, torna-se evidente que, para os usuários, a ferramenta transmite uma experiência semelhante à da máquina Braille $(\mathrm{P} 12)$, podendo ser utilizada por usuários com deficiência visual (P15) para aprender a manusear a máquina Braille (P13) e treinar seu uso (P14). Mesmo com essa semelhança (P12), um dos usuários, ressaltou a ausência, na ferramenta, da leitura tátil, proporcionada pela máquina Braille. Este aspecto é relevante para ressaltar que o Braillearning se apresenta como uma alternativa para aprender a escrita em Braille, não descartando o contato com a máquina ou com a reglete/punção, para que seja possível aprimorar o processo de leitura em Braille e a percepção tátil.

Durante a experiência dos usuários, foi possível observar também alguns aspectos, que puderam ser modificados posteriormente, de acordo com suas reações e dificuldades, como, por exemplo, os sons de efeito. Mesmo os usuários gostando desses sons, como às vezes eram reproduzidos junto com alguma resposta do sistema, acabavam dificultando a escuta de informações importantes para o uso da ferramenta. Para resolver este problema, foi adicionado um intervalo de tempo entre a reprodução de efeitos sonoros e a reprodução de respostas do sistema (e.g. leitura de caractere, palavra, dica, texto).

Os resultados apresentados apontam para a efetividade do Braillearning como uma ferramenta de auxílio à inclusão social e digital de pessoas com deficiência visual, através do uso do Braille no processo de comunicação e de socialização desse público. Aprender Braille é fundamental para a alfabetização e a interação das pessoas com DV com a sociedade, portanto, instrumentos que facilitem esse processo de aprendizagem de maneira gratuita proporcionam a ampliação dessas possibilidades.

\section{Considerações Finais}

Durante muitos anos, pessoas com diversos tipos de deficiência eram privadas da convivência em sociedade de forma igualitária, e, com isso, aspectos como a educação e 
VIII Congresso Brasileiro de Informática na Educação (CBIE 2019)

Anais do XXX Simpósio Brasileiro de Informática na Educação (SBIE 2019)

a socialização eram deixados de lado por conta da falta de possibilidades e instrumentos que pudessem se adequar à necessidade dos mesmos.

Ao longo dos anos, diversos esforços foram efetuados para desenvolver métodos e modos que permitiram tratar os desiguais, de maneira isonômica, de modo a compensar as suas desigualdades. Especificamente em relação às pessoas com deficiência visual, o Braille possibilitou a integração dos mesmos no convívio em sociedade, auxiliando-os no acesso a informações e na exposição de suas ideias.

Neste sentido, a popularização do uso de ferramentas que permitam a aprendizagem dessa linguagem é muito importante, garantindo redução de custos e fácil acesso. Deste modo, o Braillearning, detalhado neste artigo, foi criado com o intuito de cobrir a lacuna existente em relação a ferramentas populares, de maneira a facilitar o uso, o ensino, a aprendizagem e a divulgação do Braille, seja para pessoas com deficiência visual (DV), seja para videntes. A ferramenta possui desde funções básicas de ensino de letras, até funções que possibilitam o desenvolvimento de palavras e a verificação do aprendizado. Possibilita também a memorização da linguagem, podendo ser utilizada até mesmo por usuários que nunca tiveram contato com o Braille ou por aqueles que desejam desenvolver suas habilidades.

Foram efetuados testes de validação com um grupo de pessoas com deficiência visual e os resultados obtidos demonstraram que a ferramenta é útil e agradável para o aprendizado da utilização da máquina de Braille. Além disto, os usuários que testaram a ferramenta demonstraram vontade de continuar a utilizá-la, comprovando uma boa aceitação da mesma. Como consequência, a aprendizagem do Braille pode beneficiá-los no processo de inclusão sócio digital. Para tanto, é importante incentivar e difundir a ferramenta, e de outras semelhantes, na comunidade de pessoas com DV.

Uma das limitações relacionadas à execução desta pesquisa se deu em relação à análise do uso do Brailleraning para o ensino do Braille, visto que a maioria dos pesquisados já conheciam o Braille, utilizando então a ferramenta apenas para o treino e simulação da máquina de escrever.

Como trabalhos futuros, pretende-se implementar funcionalidades que permitam o armazenamento da performance do usuário, para que seja possível acompanhar o tempo de digitação de cada letra/palavra/frase, criando um sistema de pontuação, estimulando seu envolvimento através da utilização de conceitos de gamificação. Além disso, pretende-se utilizar um modo de operação multiplayer, através do qual os usuários possam jogar uns contra os outros. Ainda é possível criar uma base maior de palavras e/ou permitir que um usuário administrador/professor cadastre novas palavras ou desafios. Como a ferramenta não tem saída em Braille, outra possibilidade futura é acoplá-la a uma impressora Braille ou criar um dispositivo semelhante em hardware.

\section{Referências}

Almeida, K. P.; Paula, B, R. (2008). O sistema Braille e sua utilidade para o deficiente visual: panorama e prática. Minas Gerais: Universidade Federal de Uberlândia

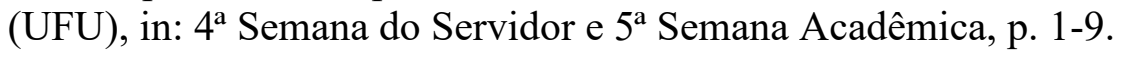

CNAIPD - Comissão Nacional do Ano Internacional das Pessoas Deficientes. (1981). Ano internacional das pessoas deficientes. Disponível em: 
VIII Congresso Brasileiro de Informática na Educação (CBIE 2019)

Anais do XXX Simpósio Brasileiro de Informática na Educação (SBIE 2019)

$<$ http://www.dominiopublico.gov.br/download/texto/me002911.pdf. $>$ Acesso em: 29- Jan- 2019.

Figueiredo, M. L. A.; Rosa, A. P. (2014). Perspectivas transversais: entre comunicação, acessibilidade e informação. In: Dito Efeito, v. 5, n. 6.

Kalra, N. et al. (2007). Iterative design of a Braille writing tutor to combat illiteracy. Bangalore: International Conference on Information and Communication Technologies and Development, p. 1-9.

Kavčič, A.; Pesek M; Marolt M. A. (2017). A platform for supporting learning process of visually impaired children. In: 40th International Convention on Information and Communication Technology, Electronics and Microelectronics (MIPRO), p. 848852. doi: 10.23919/MIPRO.2017.7973539

Mazzilli, H. N. (1999). O deficiente e o Ministério público. In: Revista Justitia, v. 50, n. 141.

MEC. (2006). Grafia Braille para a língua portuguesa, Ministério da Educação Secretaria de Educação Especial, Brasília/DF. Disponível em: $<$ http://portal.mec.gov.br/seesp/arquivos/pdf/grafiaport.pdf $>$. Acesso em: 30 Jan. 2019.

ONU - Brasil. (2019). Primeiro Dia Mundial do Braille destaca importância da linguagem escrita para os direitos humanos. Disponível em: $<$ https://nacoesunidas.org/primeiro-dia-mundial-do-Braille-destaca -importancia-dalinguagem-escrita-para-os-direitos-humanos/>. Acesso em: 29- Jan- 2019.

Osuch, P. J.; Sinha S. (2013). An electronic solution to automate the process of Grade-1 Braille training. San Jose: IEEE Global Humanitarian Technology Conference (GHTC), p. 47-52.

Pauta J. A. A.; Vélez E. P.; Serpra-Andrade, L. (2016). Braille teaching electronic prototype. Ixtapa: IEEE International Autumn Meeting on Power, Electronics and Computing (ROPEC), p. 1-7.

Resende A. R.; Filho J. B. M. R. (2012). Inserção de disciplinas de Braille na grade curricular do Ensino Fundamental da educação básica. In: Revista Benjamin Constant, v. 1, n.53.

Roth, G. A.; Fee, E. (2011).The invention of Braille. In: American journal of public health, v. 101, n. 3, p. 454.

Santana, K. C. (2018). Braillearning: ferramenta para simular a utilização da máquina de escrita em Braille. Universidade Estadual de Feira de Santana. Feira de SantanaBahia.

Velozo, M. L. (2015). A Importância do Uso da Máquina de Escrever Especial em Braille para os Deficientes Visuais (Cegos). Curitiba-PR. Disponível em: $<$ http://datamarcos.blogspot.com.br/2015/06/datamarcos-importancia-do-usoda.html>. Acesso em: 30- Jan- 2019. 